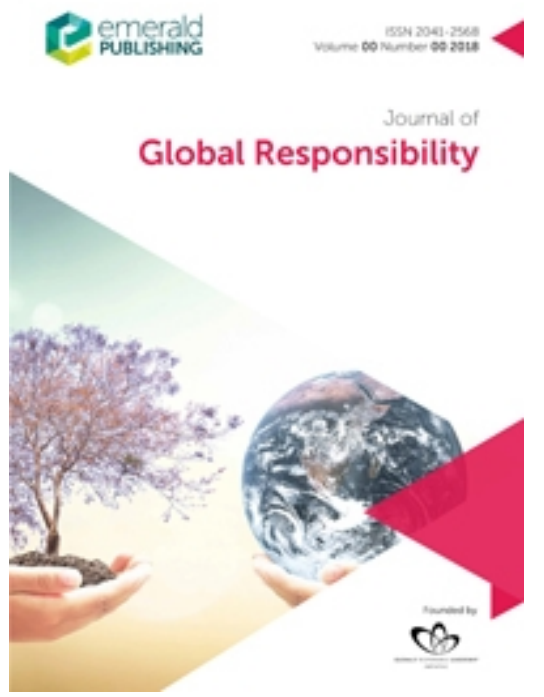

\title{
Responsible Education: What Engages International Postgraduate Students - Evidence from UK
}

\begin{tabular}{|r|l|}
\hline Journal: & Journal of Global Responsibility \\
\hline Manuscript ID & JGR-03-2020-0036.R1 \\
\hline Manuscript Type: & Refereed Article \\
\hline Keywords: & $\begin{array}{l}\text { Sense of Belonging, Student Engagement, Student Experience, Teaching } \\
\text { and Learning Pedagogy, International Students }\end{array}$ \\
\hline \multicolumn{2}{|l}{} \\
\hline
\end{tabular}

\section{SCHOLARONE \\ Manuscripts}




\title{
Responsible Education: What Engages International Postgraduate Students - Evidence from UK
}

\begin{abstract}
Purpose: Responsive educational approaches focus on a set of well-designed practises intended to create engaging, social cohesion, better knowledge outcomes and excellent students experience. Therefore, this article engages in the discourse of the intersection of psychsociology of learning and student's engagement, connected to the sense of belonging and theory of planned behaviour (TPB).

Methodology: By applying an ethnographic approach and interview of 45 international students from three UK business schools, it proposes that a sense of 'belongingness' is a prerequisite for learning, personal and professional development. Due to the exploratory nature of the subject, the use of qualitative methodology turned out to be particularly useful. Indeed, the conduct of in-depth semi-structured interviews, participative observation enabled us to access perceptions of students and compare different points of view.
\end{abstract}

Findings: The findings indicate that international students measure their experience by 'sense of belonging', integration and engagement on many interrelated and influential factors. English proficiency and employability skills are major concerns. The kinds of support students received and the quality of feedback from tutors is important for International studies integration and sense of belonging.

Originality: The findings of the critical elements of the engagement and experience of international students have both policy and practical implications given the high demand for UK universities by foreign students. Although, this article is based on findings from UK higher education institutions (HEIs), the insights are of relevance to many countries such as Australia, Canada, Germany, France and the US who have a significant proportion of overseas students.

Keywords: Sense of Belonging; Student Engagement; Student Experience; Teaching and Learning Pedagogy; International Students.

\section{Introduction}

The ongoing relationship between educational institutions and their students is nicely captured by the notion of student engagement and experience (Bernardo, Butcher \& Howard, 2012; Kyriakidesa, Stylianou \& Menon, 2019). International students studying at higher education institutions (HEIs) in different countries experience challenges as they adjust to new environments (Rivas, Burke \& Hale, 2019). Hence, there is an increasing focus on student experience and improving engagement as a central goal of effective pedagogy (Dunbar \& Carter, 2017). Students enrol in higher education to gain subject or discipline knowledge to achieve social and economic benefits (Samier, 2015). To help them achieve these requires "a teaching approach which begins to satisfy simultaneously a tacit demand for content, for the understanding of content, for relevance and applicability of that content ..." (Zepke, 2013: 99).

How students engage with their studies has become an interesting area of research in recent times (Chrystal \& Mwangi, 2016; García, Garza \& Yeaton-Hromada, 2019; Tang, Collier \& Witt, 2018). Therefore, research into student engagement and factors supporting or hampering the learning outcomes of students or what encourages passive learning is required 
to guide the curriculum development and teaching practices (Nind \& Lewthwaite 2018). Of course, student development is an all-embracing concept that involves research focusing on students from recruitment to placement (Machado et al., 2011). Also, Students' conceptions of teaching and assessment have been shown to relate significantly to academic performance (Flores et al., 2019; Tang, Collier \& Witt, 2018).

It appears that for students who cross boundaries between practice and academic placements, a sense of 'belongingness' is a prerequisite for learning for personal and professional development (Dunbar \& Carter, 2017; Gillen-O’Neel, 2019). Rather than looking at the perceptions that students have of their learning, useful though these are, this article evaluates students' engagement to offer new ways of understanding the experiences of international students. This is crucial since enhancing graduate knowledge, skills and employability is a priority for many stakeholders (Alvarez-Gonza'lez et al., 2017). Drawing on Ajzen (1991) theory of planned behaviour (TPB), this study argues that engagement occurs in psychosocial space and cognitive structures (Heuer \& Kolvereid, 2014) formed by the complex interaction of student and learning environment, within which the student experiences higher education.

Most research on the sense of belonging in higher education has relied upon betweenperson correlations (Gillen-O'Neel, 2019; García, Garza \& Yeaton-Hromada, 2019). In the current study, an ethnographic approach is preferred that enables the identification, observation and interview of 45 international postgraduate students (from 12 countries outside the European region) from three UK business schools. The rationale for focusing on international students is that despite the growing numbers of international students into Australia, Canada, UK and the US, studies focusing on foreign students are limited (Courtois \& Veiga 2019; García, Garza \& Yeaton-Hromada, 2019; Tang, Collier \& Witt, 2018; Chrystal \& Mwangi, 2016). More so, the shifts in funding and a worldwide trend towards 'marketizing' higher education have led to a new emphasis on the quality of students' experience (Staddon \& Standish, 2013). In the UK, this trend finds its strongest expression since the government embarked on increasing tuition fees and student choice so that students themselves become the drivers of higher education (Staddon \& Standish 2013, p.10).

In what follows, this article explores the broader context of higher education highlighting the impact of the quality of teaching and learning, implementation of teaching and students' experience. This is followed by a discussion on sense of belongings, planned behaviour, methodology, the findings, analysis and conclusion.

\section{Teaching Quality and Learning outcomes}

Some studies describe the importance of psychosocial learning environments in education, and how these can help achieve environmental learning goals (Ormond \& Zandvliet, 2014). Indeed, quality of learning in higher education involves a variety of interacting variables - teachers, learners, subject matter (content) and learning-teaching processes (pedagogy) - operating in dynamic yet connected networks (Zepke, 2013). Instructors' teaching styles in higher education are an issue of major importance because these interactions affect students' self-perceptions, involvement, and achievement (González et al., 2018). In their study, Zepke and Leach (2010) develop a conceptual organizer for student engagement that consists of four perspectives: student motivation; transactions between teachers and students; institutional support; and engagement for active citizenship.

It appears that in comparison to teaching, research excellence and impact dominate the higher education agenda, particularly concerning how the overall quality of HEIs is assessed, evaluated and teachers rewarded (Cadez, Dimovski \& Groff 2017). Rata (2017) argues that the link between the way knowledge is structured and the way it is organised for teaching justifies instructional teaching as a more effective way to develop students' learning. The Higher 
Education Academy (2015: 3) emphasizes that "embedding equality and diversity in the curriculum is the creating of learning, teaching and assessment environments and experiences that proactively eliminate discrimination, promote equality of opportunity and foster good relations in a manner that values, preserves and responds to diversity". Also, there is evidence that student engagement - the student's emotional, behavioural, and cognitive connection to their study has an important influence on student learning, retention and success (Gustafsson \& Fagerberg, 2004).

\section{Sense of Belongings, Student's Engagement and Experience}

Baumeister and Leary's (1995) "belongingness hypothesis" proposed that belonging is a fundamental human motivation and, as such, it has positive affective and behavioral consequences (Gillen-O'Neel, 2019). Students' sense of belonging (Hausmann, Schofield \& Woods, 2007) and place belongingness' are related to the attachment of an individual experience of a particular place and the extent to which they perceive themselves as being an integral part of a place (Dunbar \& Carter, 2017). In their study Lampinen et al. (2018) list six categories of factors that foster a sense of belonging (open interaction, effective conversation culture, support and encouragement, common values, a shared vision of the work and its objectives and structure of leadership). The importance of attachments to places has been articulated in the literature as significant in the development of self-identity and can determine how individuals associate place with an identity (Dunbar \& Carter, 2017). The degree to which people can experience a sense of 'at-homeness' with a place is influenced by the depth of the relationship they develop (Dunbar \& Carter, 2017).

Gillen-O'Neel (2019) found that a sense of belonging was associated with all types of student engagement at both the person and the daily levels. The findings reveal that at the personal level students with a higher sense of belonging than their peers tended to also have higher emotional and behavioral engagement. It also found that at the daily level, regardless of students' typical sense of belonging, if they experienced a high sense of belonging on a particular day, their emotional and behavioral engagement on that same day tended to be higher than usual (Gillen-O’Neel, 2019). Although research has explored how in-class pedagogical practices affect student engagement and motivation, questions remain on several elements such as the impact of grading systems on academic motivation (Chamberlin, Yasué \& Chiang, 2018), feedback and how best to provide it to promote learning and the use of information and communication technology integration to increase student engagement (Vahedi, Zannella \& Want, 2019).

Previous studies measuring student's experiences have adapted students' surveys or reflective logs. As such some studies focus on reflection and the advantages that can be gained from the practice of reflection (Gustafsson \& Fagerberg, 2004). Reflective practice, as a practice model, is generally espoused as a developmental process to empower practitioners to achieve and sustain effective practise (Gravett \& Winstone, 2019; Flores et al. 2019; Chamberlin, Yasué \& Chiang, 2018), hence we have adopted student's reflection for this study, linked to planned behaviour to evaluate student learning experience.

Students' generation of content has been advocated as a means of fostering deep learning and high levels of student's engagement, leading to enhanced conceptual understanding (Doyle, Buckley \& Whelan 2019). As such, instructors often incorporate selfand peer evaluations in students learning (Ohland et al., 2013). Also, there is considerable evidence that effective feedback leads to learning gains (Caton, Govan \& Zahn 2018). Coaching, career counselling and internships are other elements that contribute to the student 
experience by helping students develop relevant professional skills and soft skills, connect with professionals, and acclimate to the world of work (Nghia \& Duyen, 2019).

\section{Theory of Planned Behaviour}

The use of theory is imperative to enhancing our understanding of a certain phenomenon or element as it provides a useful basis to describe, explain and predict the phenomena (Hew et al., 2019). At the same time, higher education research is the resultant outcome of many disciplines, and higher education researchers use many borrowed concepts or theories which are then "filled" with content that pertains to the specificity of their research object (Szadkowski, 2019). Learning has traditionally been described as a change in behaviour or cognitive processes, with a focus on demonstrating a unidirectional transfer of a stable body of knowledge (Carvalho \& Yeoman, 2018). The theory of planned behaviour (TPB) (initially developed by Ajzen (1991), focuses on attitudes, subjective norms and perceived behavioural control) seeks to understand intentions that can help measure actual individual behaviour. Cognitive structures can include an individual's underlying behaviour that can be influenced by information content (Krueger, 2009).

In their study, Burns, Houser and Farris (2018), utilizes the TPB to examine an instructor confirmation-interaction model in the instructional communication context to discover a means by which instructors might cultivate positive student attitudes and increase beliefs that interactions with instructors would be beneficial in the future. Both perceptions of environmental factors (Shahab et al., 2018) and intentions as determinants of action are included in the theory of reasoned action and TPB developed by Ajzen \& Fishbein (1980) which postulated that a person forms an intention to engage in certain behaviour. Arguably, intentions are indicators of how hard people are willing to try and how much effort they are willing to expend to act (Poulou \& Norwich 2013). Therefore, intentions can be deemed as motivators of behaviour. There have been several studies on the elements of the TPB towards school completion, students' academic attainment and as a cognitive predictor of action (Freeney \& O'Connell 2013; Poulou \& Norwich 2013). In this study, we adopt the TPB and use it to evaluate the engagement, behaviour and students' learning outcomes. Using semistructured interviews, the research questions guiding this study focused on questions but not limited to;

- How has the teaching and learning adopted in the business schools enabled or not enabled a sense of belonging and the achievement of vital knowledge or skills?

- What were the strengths and weaknesses of some of the teaching methods and what engages or disengages students?

- How have some of the teaching, activities and assignments enabled or not enabled the facilitation of learning, skills, career development and experience?

\section{Methodology}

Based on qualitative methods (Courtois \& Veiga, 2019), this article draws on evidence from 45 international postgraduate students from three Business schools in the UK between 2017 and 2018 - chosen based on the authors' institutions where access to students was given. We employed an ethnographic approach involving interviews, observations and field notes, as a way of recording the events and experiences (Van Maanen, 2011). Due to the exploratory nature of the subject, the use of qualitative methodology turned out to be particularly useful (Rahman et al., 2019). Indeed, the conduct of in-depth semi-structured interviews, participative 
observation enabled us to access perceptions of students that were accessible only "from the inside" and compare different points of view, on questions that are not easily conceivable by quantitative method (Merino, Lavissie're \& Mandja'k, 2018).

Observations were made during three workshops per module (I hour x 3 sessions $\mathrm{x} 3$ modules), making a total of 9 hours observation for each selected business school. This adds up to a total of 27 hours observations from October 2017 to December 2018. During that time, the researchers also observed joint meetings of student's group sessions from three selected modules. Also, 30 to 60 minutes long interviews were conducted with the students. The analysis in this paper is based on the interviews and observations. Also, three focus groups comprising 5 students each (total of 15 students) were undertaken as a means of validation and confirmation of the emerging data from interviews and observations.

Although students were selected from the authors' institutions, none of the authors was involved in observing and interviewing selected students from their institutions. This is to eliminate bias and maintain information quality. Also, we followed and observed the ethical process by selecting students or groups who freely volunteered to be observed and interviewed. Selected students and groups were asked to sign consent forms where the aims and objectives of the study were explained. Also, explained in the form, is that participation is voluntary and opportunity to withdraw from the study or interview is allowed at any time. Also, confidentiality and anonymity were guaranteed, and no sensitive information will be published. The students were assigned pseudonyms to preserve their anonymity. The ages of the students ranged from 22 to 30 years, and their nationality includes China, Nigeria, South Africa, India, Malaysia, Ghana, Vietnam, Hong Kong, Thailand, Japan, Kenya and South Korea.

All the students interviewed have the experience of studying in the business school for at least nine months proceeding to the interview. The interviews were recorded and examined independently concerning phrases and sentences that characterised the critical research questions. Transcripts were coded using the qualitative data analysis software NVivo, which helped to identify and explore concepts and categories, trying to find the best fit or most plausible explanation for the relationship under study. To analyze the data, direct and typical quotations from the text responses were marked with an identification code concerning the research questions using 'thematic analysis' (Al-Mataani, Wainwright \& Demirel, 2017) to identify dominant themes.

The data analysis followed a robust and systematic process familiar with qualitative research as previously undertaken by scholars such as Al-Mataani et al. (2017). First, data were coded into main themes by assigning a word or phrase to each category as presented in the findings section. Second, through axial coding, data are put back together in new ways by making connections between themes. In the third step, selective coding was performed through selecting illustrative quotes that matched the themes which formed the basis for our analysis, interpretation and discussion.

\section{Findings and Analysis}

\section{Student Engagement and Learning Outcomes}

The students interviewed provided an account of the depth of information and content of the programmes that they were enrolled in. Most of the students maintained that these were up to high standards as they anticipated. Some pointed to the visual content of the lectures and the virtual resources on the digital blackboard/portal that help students learn which is different from the approaches in their home countries. We are living in a modern age of visual and online communication. This development has partly been reflected in this study as some students stressed the importance of additional resources that support classroom learning as is exemplified in the following quotations; 


\section{[....] I like how besides the availability of lecture and seminar resources provided by the tutors; extra or supplementary notes were also provided on the digital platforms to give additional guidance to help us understand more about the topics (R.02)}

Most of the students noted that most of their teaching was supported with case studies during a follow-up seminar which helped them to understand the subjects better and how to tackle the assignments. It is not just enough to provide additional resources or visual resources; the quality should be of a high standard to contribute to higher knowledge and competencies. There have been previous studies based on understanding the behaviour and learning outcomes of students. Linked to Ajzen and Fishbein's TPB (1980) problem-based learning and virtual resources, information and communication technology integration can be effective methods of increasing student engagement and sense of belongings. Hence, there is recognition by students of the importance of teaching that enhances student's engagement and learning experience;

[....] I like the practical, creativity and reality aspect of some modules. The depth of information and contents of the programme is just right and exciting and wellstructured creating a positive learning environment (R.04).

English language proficiency is a major problem like the findings from Tang et al. (2018) on Chinese Students' Perception of USA University life. International students are mainly nonEnglish speakers and come from countries where English is neither used to teach in primary, secondary schools and university levels. Hence, most of the students are expected to learn and pass the English language test within 6 months and up to one year before they are admitted to UK higher education. Hence, the ascent and speed of speeches in English become a barrier to many international students. Many of the students interviewed acknowledged that this is one of the challenges they face in learning in the UK higher education. Some of the participants noted that some tutors ignored the fact that many do not have the same English language competencies with home students during their teaching.

International students not only have language barriers but also cultural shocks which impact on learning experiences and behaviours. From the interviews, it was evident that because of the cultural background of the students, many international students prefer to listen than ask questions in the class which is out of respect for the teachers. They prefer activities that allow them to interact with fellow students while the tutor moderate or offer advice when necessary;

[...] as a student who doesn't like attention, I tend to learn best by observing others and listening. The seminars and lectures where tutors would call out individual students to give their opinions in front of the class were the worst for me (R.03).

During the observations on the class activities and self-directed activities (group work), there was a noticeable difference between the level of engagement and interactions among international students according to nationalities. We observed that Chinese, Thailand and Hong Kong students tended to work more closely with each other and communicated effectively in their language when grouped and less when grouped with diverse nationalities. Whereas, Africans, India and Vietnamese students engaged and communicated effectively when grouped in multi-diverse nationalities. Also, during the observation, it was clear that groups which had home students were dominated by the English students while the others (like the Chinese) barely participated or engaged in the discussions. During the interviews, students were asked to explain the different and underlying causes of the differences in communications and interactions. From their responses, it was obvious that language was a major determinant factor (for the Chinese) and culture (for the Africans and Indians). Also, when asked which skills that 
We asked the students to reflect and describe teaching and learning that they have undergone which had a positive or negative impact on their learning and sense of belonging. The students described some of the best practices that helped them to adapt to the teaching and learning environment and enabled them to excel. These types of responsive classroom approaches to teaching focus on a set of well-designed practises intended to create engaging classrooms and better learning outcomes. Some of the students suggested that emphasis should be on helping students to develop their knowledge that is developmentally responsive to their strengths, needs and weaknesses. Students liked;

[....] teaching that focused on practical activities and projects that enable students to research, discover and develop new knowledge (R.018).

Arguably, positive interactions between teachers and students could influence student behaviour and attitude. Many of the students emphasise that cordial interactions between tutor and student were vital towards their learning. Some point to best practices which influences students' experience and learning outcomes such as the duration of lectures, introduction of interactive activities, stories and live cases. They point out that many students are unable to concentrate effectively on long hours teaching sessions;

[...] my opinion, if possible, divide a two-hour lecture into two separate one-hour lectures and a one-hour workshop (R.01).

Majority of the students interviewed identified seminars as one of the best forms of engagement;

My feeling is that the teaching methods worked well. I prefer the seminar which is more diverse and interactive (R.023)

I think workshops encourage more interactions, not only for the assessments but the chance to learn from fellow students and the tutor (R.06).

Seminars are understood to be a small group learning in which students and a tutor discuss information on a chosen topic that relates to the main topic of interest. They may be called something else such as tutorial classes or workshops. Seminars provide an opportunity to explore topics by discussion, and to identify and sort out any problems. Some tutors may use the opportunity to introduce new topics or explore previous issues. Most seminars last for an hour. Of course, the best teaching and learning strategies prepare learners to collaborate (Blackler \& McDonald, 2000), a view that is shared by some of the students;

[....] I prefer the activities we did on some modules where we were divided into groups to list our thoughts onto paper and discuss it (R.09).

I like group work as it enables me to see other viewpoints without the awkwardness of standing up in front of everyone and potentially making a fool of myself (R.011). 
Of course, team working is another important skill that students need to develop during their studies. Indeed, humans are social beings, and our survival depends on working and living collaboratively (Baldwin, 2019). The more teamwork exhibited, the more opportunity exists for students to learn, collaborate and evaluate themselves;

\section{[...] focus on teamwork, many businesses model and operations are organised in teams} (R. 019).

In today's education, there is an increasing interest in the assessment framework. Grading alone does not sufficiently promote student learning. Some of the International students advocate for interactive assessments that allow voluntary participation rather than a compulsory assignment with no options to choose from. Some of the students offered suggestions on how to improve assessments, feedback, teaching and learning activities. Here are some examples of responses;

[...] I would like to see more formative activities and assignments that do not contribute to module grade to allow me to experiment, make mistakes and learn from it (R.013).

Feedback on assignments should be more detailed, to help International students realise what they lack and how to do better next assignment (R.031).

Installing facilities that record lectures and post on the blackboard to enable students who struggle with teachers' accents or miss classes to watch it will be beneficial for exam revision and personal study (R.023).

Some of the students stated that assignments should have focus and not too many instructions that lead to confusion. They proposed that tasks should be straightforward with explicit instructions to follow. Some of the students advocate having many options of assignment and coursework such that there will be 3 or 4 options to choose from;

[...] the options should have coursework activities that focus on developed and developing country context to enable international, and home students choose which option they have the knowledge and relevant to them [....] (R.013).

[...] regarding the bad experience, I struggled with some assessment focusing only on Western contexts (R.44)

[...] there is a need to tailor the academic requirement of home students different from International students, especially, projects and coursework (R.35).

Some of the students suggested pedagogical measures that encourage students to participate in activities such as the introduction of peer-assessments and reflective assignment because it motivates all students to contribute to completing a task and sharing knowledge. They pointed to best practices such as allocation of personal tutor and module evaluation processes which enable student's opinion and feedback. Some advocated for the design of teaching that enables student's creativity and thinking in the form of use of experiential and practical knowledge;

I like real-life cases or evidence such as showing videos and games (R.45).

International students come from many different and diverse cultural backgrounds. Hence, English culture, values and behaviours are new to them. Teachers must adopt measures that 
encourage equality and diversity and develop students' understanding of local culture and social knowledge to aide a sense of belongings;

In addition to the demand for knowledge, I still want to integrate and experience the local culture and life. I hope that the university will be my second home (R.025).

\section{Student Experience}

During the interview, students acknowledged the kinds of support they received from their faculties which provided a sense of belongings. Many of the participants point to best practices in which business faculties provide a lot of resources such as library support, digital resources, language support and one-to-one personal tutor support. However, some felt the teaching content could be a bit richer with information in some courses and focus on experiential teaching by offering real-life cases and activity. Some of the student's provided examples of some learning experiences and activities that enable students to develop knowledge and practical skills;

[...] I liked speeches by a real-life entrepreneur as guest lecturers (R.38).

Yes, the excursion and industry visits to some companies was very exciting (R.42)

[...] the tutor provided the opportunity for students to interact with local business people which made the experience very exciting (R.017).

Besides expressing the best practices and not so good experiences during their studies, participants provided suggestions on how to promote 'inclusive learning for all' and improve international students' sense of belongings. Some suggested that modules should be designed to incorporate practical activities that increase entrepreneurial spirits, such as allowing students to participate in corporate live-projects and practical not limited to paper case studies;

This my first time abroad as an international student. I study MSc in [....]. I have both good and bad experiences while studying at the University of [....] (R.05)

On the good experience, I gain more knowledge about my subject majors such as [....]. There were outstanding experiences from some modules that had field trips to visit events and attractions which increased my experience and understanding (R.05).

On the negative side - I feel there were too many assignments and coursework which did not provide the opportunity for practice learning (R.05)

Some of the students suggested examples of Nudges that could be incorporated into learning activities such as activities that take students out of their comfort zone, competitions with rewards, networking (such as - free food or free pizza activities), student-led activities, nochair activities, outdoor activities, etc. Many students like to see more activity-based learning that is non-assessed that provide elements of creativity. Such group activities should enable diversity, intercultural learning and participation. It is expected that through the exchange of personnel with relevant professionals, students can gain a deeper understanding of the professional skills, ways of thinking, and cognition;

We often receive emails from the faculty about opportunities for part-time work and voluntary activities. This is great (R.043).

I also hope that [....] can provide more opportunities for internships in local companies for International students (R.029). 


\section{Discussion, Implication and Conclusion}

Although the notions of quality of teaching are necessarily varied across disciplinary settings, studies show that the teaching methods and practices influence students' learning and engagement (Cadez et al., 2017; Fan, 2012; Henard \& Roseveare, 2012). Hence, in this study, students' experience and learning outcomes are seen as depending on many interrelated and influential factors. Our findings reveal that English language proficiency as a major challenge, especially for the Chinese, Hong Kong and Thailand students. Africa, Indians, Malaysia and Vietnamese were more concerned about the cultural differences. Students from various backgrounds highlighted the importance of engagement, feedback and the kinds of support students receive from teachers and faculties as critical factors to their overall experience and sense of belongings. Students from all backgrounds highlighted the importance of feedback from tutors and live activities as crucial to their engagement and sense of belongings.

From the student's perspectives, International students measure their experience by a sense of belongings, integration and engagement. Hence, HEIs must provide teaching methods and curricular and extracurricular activities which enable students to acquire knowledge, skills and experience required to succeed in the labour market. This study contributes to knowledge of what engages or disengages students or determines students behaviour and factors supporting or hampering the achievement of learning outcomes. Vahedi, Zannella and Want (2019) propose that information and communication technology integration can be an effective method of increasing student engagement. More so, the importance of faculty support, guidance and counselling has been emphasised in many studies (see, e.g. Christie, 2016) as crucial factors that contribute to a student's experience - positively.

Another contribution of this study is that it provides an opportunity for students to state their perspective voluntarily and freely. Of course, the demand for improvement in knowledge and skills are the main factors influencing the demand for overseas education by many international students. While many international students will continue to travel overseas for their education, they must be given opportunities to express their views on the issues and barriers that affect their learning and development. Therefore, more research is required to focus on examining the sense of belongings of students. If international Students experienced high disaffection of overseas' education systems or methods, these could have implications on student recruitment and retention. Therefore, adequate educational practices and policies are required to improve international students' experiences.

Finally, the ethnographic approach was adopted in this study that enabled the observation and interview of 45 students from three UK business schools and a critical literature review. This approach allowed the authors to be immersed in the events settings, interacting, observing and questioning and undertaking the role of 'observer and participant' (Crowther, Orefice \& Beard, 2018). Despite the strength of the qualitative methods, the validation process and richness of the data, there are limitations related to the size of the sample used in this study and the scope of the study. However, the insights are of relevance to offer critical knowledge about the experience and sense of belongings of international students and provide a very good foundation for future studies.

\section{References}

Ajzen, I. 1991. The theory of planned behaviour, Organizational Behavior and Human Decision Processes, 50(2), 179-211.

Ajzen, I. and Fishbein, M. 1980. Understanding Attitudes and Predicting Social Behaviour. Englewood Cliffs, NJ, Prentice-Hall 
Al-Mataani, R., Wainwright, T. and Demirel, P. 2017. Hidden Entrepreneurs: Informal Practices within the Formal Economy. European Management Review, 14, 361-376

Alvarez-Gonza'lez, P., Lopez-Miguens, M.J. and Caballero, G. 2017. Perceived employability in university students: Developing an integrated model. Career Development International, 22(3): 280-299.

Baumeister, R. F. and Leary, M. R. 1995. The need to belong: Desire for interpersonal attachments as a fundamental human motivation. Psychological Bulletin, 117(3), 497529. In: Gillen-O’Neel, C. 2019. Sense of Belonging and Student Engagement: A Daily Study of First- and Continuing-Generation College Students. Research in Higher Education, 2019. https://doi.org/10.1007/s11162-019-09570-y

Bernardo, M. A. C., Butcher, J. and Howard, P. 2012. An international comparison of community engagement in higher education, International Journal of Educational Development, 32(1), 187-192,

Blackler, F. and McDonald, S. 2000. Power, Mastery and Organizational Learning. Journal of Management Studies, 37(6), 833-852

Burns, M.E., Houser, M.L. \& Farris, K.L. 2018. High Education, 75: 1091-1099 https://doi.org/10.1007/s10734-017-0187-0

Cadez, S., Dimovski, V. and Groff, M. Z. 2017. Research, teaching and performance evaluation in academia: the salience of quality. Studies in Higher Education, 42(8), 1455-1473, DOI: 10.1080/03075079.2015.1104659

Canton, U., Govan, M. \& Zahn, D. 2018. Rethinking academic literacies. A conceptual development based on teaching practice. Teaching in Higher Education, 23(6), 668-684

Carvalho, L. and Yeoman, P. 2018. Framing learning entanglement in innovative learning spaces: Connecting theory, design and practice. British Educational Research Journal, 44(6), 1120-1137.

Chamberlin, K., Yasué, M. and Chiang, I.-C. A. 2018. The impact of grades on student motivation. Active Learning in Higher Education. https://doi.org/10.1177/1469787418819728

Christie, F. 2016. Careers guidance and social mobility in UK higher education: practitioner perspectives. British Journal of Guidance \& Counselling, 44(1), 72-85

Chrystal A. and Mwangi, G. 2016. Exploring Sense of Belonging among Black International Students at an HBCU. Journal of International Students, 6(4), 1015-1037

Courtois, A. \& Veiga, A. 2019. High Education, (2019). https://doi.org/10.1007/s10734-01900439-8

Crowther, P., Orefice, C. and Beard, C. 2018. At work and play: Business events as entrepreneurial spaces. The International Journal of Entrepreneurship and Innovation, 19(2), 90-99

Donnelly, M. \& Evans, C. 2019. A 'home-international' comparative analysis of widening participation in UK higher education. Higher Education, (2019) 77:97-114 https://doi.org/10.1007/s10734-018-0260-3

Dunbar, H. and Carter, B. 2017. A sense of belonging: The importance of fostering student nurses' affective bonds. Journal of Child Health Care, 21(4), 367-369.

Flores, M. A. and Brown, G., Pereira, D., Coutinho, C., Santos, P. \& Pinheiro, C. 2019. Higher Education. Portuguese university students' conceptions of assessment: taking responsibility for achievement. Higher Education, (2019) https://doi.org/10.1007/s10734-019-00415-2

Freeney, Y. \& O'Connell, M. 2013. The predictors of the intention to leave school early among a representative sample of Irish second-level students. British Educational Research Journal, 38(4), 557-574 
García, H. A., Garza, T., and Yeaton-Hromada, K. 2019. Do We Belong? A Conceptual Model for International Students' Sense of Belonging in Community Colleges. Journal of International Students, 9(2), 460-487

García, M. C. D. and Welter, F. 2011. Gender identities and practices: Interpreting women entrepreneurs' narratives. International Small Business Journal, 31(4): 384-404.

Gault, J., Leach, E. and Duey, M. 2010. Effects of business internships on job marketability: the employers' perspective. Education and Training, 52(1), 76-88.

Gillen-O'Neel, C. 2019. Sense of Belonging and Student Engagement: A Daily Study of First- and Continuing-Generation College Students. Research in Higher Education, (2019). https://doi.org/10.1007/s11162-019-09570-y

González, A., Conde, Á., Díaz, P. et al. 2018. High Education, 75: 625. https://doi.org/10.1007/s10734-017-0160-y

Gravett, K. and Winstone, N. E. 2019. Feedback interpreters: the role of learning development professionals in facilitating university students' engagement with feedback. Teaching in Higher Education, 24:6, 723-738 DOI: $10.1080 / 13562517.2018 .1498076$

Gustafsson, C. \& Fagerberg, I. 2004. Reflection, the way to professional development? Journal of Clinical Nursing, 13(3), 271-280

Hausmann, L. R. M., Schofield, J. and Woods, R. 2007. Sense of belonging as a predictor of intentions to persist among African American and White first-year college students. Research in Higher Education, 48(7), 803839. https://doi.org/10.1007/s11162-007-9052-9.

Henard, F. and Roseveare, D. 2012. Fostering quality teaching in higher education. Paris: OECD Institutional Management in Higher Education.

Heuer, A. \& Kolvereid, L. 2014. Education in entrepreneurship and the theory of planned behaviour. European Journal of Training and Development, 38(6): 506-523.

Hew, K. F., Lan, M., Tang, Y., Jia, C. and Lo, C. H. 2019. Where is the "theory" within the field of educational technology research? British Journal of Educational Technology, $50,3,956-971$

Higher Education Academy 2015. Embedding equality and diversity in the curriculum: a model for learning and teaching practitioners.

https://www.heacademy.ac.uk/system/files/eedc model for learning and teaching pr actitioners.pdf Accessed: 03/06/2018

Jacklin, A. and Robinson, C. 2007. What is meant by 'support' in higher education? Towards a model of academic and welfare support. Journal of Research in Special Educational Needs, 7(2), 114-123

Jaskiewicz, P., Combs, J.G. and Rau, S.B. 2015. Entrepreneurial legacy: toward a theory of how some family firms nurture transgenerational entrepreneurship. Journal of Business Venturing, 30(1), 29-49.

Kelly, P., Hohmann, U., Pratt, N. and Dorf, H. 2013. Teachers as mediators: an exploration of situated English teaching, British Educational Research Journal, 39(4), 609-634

Knight, D. B. and Novoselich, B. J. 2017. Curricular and Co-curricular Influences on Undergraduate Engineering Student Leadership. The Research Journal of Engineering Education, 106(1), 44-70

Krueger, N.F. 2009. The micro-foundations of entrepreneurial learning and ... education: The experiential essence of entrepreneurial cognition, in West, G.P., Gatewood, E.J. and Shaver, K.G. (Eds) Handbook of University-wide Entrepreneurship Education, Edward Elgar, Cheltenham

Kyriakidesa, L., Stylianoub, A. and Menon, M. E. 2019. The link between educational expenditures and student learning outcomes: Evidence from Cyprus. International 
Journal of Educational Development, 70 (2019) 102081 https://doi.org/10.1016/j.ijedudev.2019.102081

Lampinen, M., Konu, A., Kettunen, T. and Suutala, E. 2018. Factors that foster or prevent sense of belonging among social and health care managers. Leadership in Health Services, 31(4), 468-480. https://doi.org/10.1108/LHS-09-2017-0054

Machado, M. L., Brites, R., Magalhães, A. and José Sá, M. 2011. Satisfaction with Higher Education: critical data for student development, European Journal of Education, 46(3), 415-432

Mark, L. J., Wierika, T., Beishuizenb, J. and van-Osb, W. 2015. Career guidance and student success in Dutch higher vocational education. Studies in Higher Education, 40(10), 1947-1961

Merino, P. B., Lavissie 're, A. and Mandja 'k, T. 2018. Emergence of a higher education born global in Africa: The role of the business network. The International Journal of Entrepreneurship and Innovation, 19(3), 194-206

Nghia, T. L. H. and Duyen, N. T. M. 2019. Developing and validating a scale for evaluating internship-related learning outcomes. Higher Education, (2019) 77:1-18 https://doi.org/10.1007/s10734-018-0251-4

Nind, M. \& Lewthwaite, S. 2018. Methods that teach: developing pedagogic research methods, developing pedagogy. International Journal of Research \& Method in Education, 41:4, 398-410, DOI: 10.1080/1743727X.2018.1427057

Ohland, M. W., Loughry, M. L., Woehr, D. J., Bullard, L. G., Felder, R. M., Finelli, C. J., Layton, R. A., Pomeranz, H. R. and Schmucker, D. G. 2013. The Comprehensive Assessment of Team Member Effectiveness: Development of a behaviourally Anchored Rating Scale for Self- and Peer Evaluation. Academy of Management Learning and Education, 11(4)

Ormond C.G.A. and Zandvliet D.B. 2014. Learning Environments in Higher Education. In: Zandvliet D., Brok P.., Mainhard T., Tartwijk J. (eds) Interpersonal Relationships in Education. Advances in Learning Environments Research. Sense Publishers, Rotterdam

Poulou, M. and Norwich, B. 2013. Cognitive, Emotional and Behavioural Responses to Students with Emotional and Behavioural Difficulties: A model of decision-making, British Educational Research Journal, 28(1), 111-138

Rahman, M., Billah, M. M., \& Hack-Polay, D. 2019. What is hindering change? Anticipating the barriers to the adoption of enzyme-based textile processing in a developing country. Business Strategy \& Development, 2(2), 137-147.

Rainey, K., Dancy, M., Mickelson, R. et al. 2018. Race and gender differences in how sense of belonging influences decisions to major in STEM. IJ STEM Ed, 5: 10. https://doi.org/10.1186/s40594-018-0115-6

Rata, E. 2017. Knowledge and teaching. British Educational Research Journal, 43(5), 10031017

Rivas, J., Burke, M. and Hale, K. 2019. Seeking a Sense of Belonging. Journal of International Students, 9(2), 682-704. https://doi.org/10.32674/jis.v9i2.943

Samier, E. A. 2015. The globalization of higher education as a societal and cultural security problem. Policy Futures in Education, 13(5), 683-702.

Shahab, Y., Chengang, Y, Arbizu, A. D. and Haider, M. J. 2018. Entrepreneurial self-efficacy and intention: do entrepreneurial creativity and education matter? International Journal of Entrepreneurial Behavior \& Research https://doi.org/10.1108/IJEBR-12-2017-0522

Staddon, E. \& Standish, P. 2013. Improving the Student Experience. (Eds): Smith, R. (2013) Education Policy: Philosophical Critique. British Educational Research Journal, https://doi.org/10.1002/9781118680544.ch10 
Szadkowski, K. 2019. High Education, (2019) 78: 241. https://doi.org/10.1007/s10734-0180340-4

Tang, X., Collier, D. A., and Witt, A. 2018. Qualitative Study on Chinese Students' Perception of U.S. University Life. Journal of International Students, 8(1), 151-178

Vahedi, Z., Zannella, L. and Want, S. C. 2019. Students' use of information and communication technologies in the classroom: Uses, restriction, and integration. Active Learning in Higher Education. https://doi.org/10.1177/1469787419861926

Van Maanen, J. 2011. Tales of the Field: On Writing Ethnography, University of Chicago Press, Chicago, IL.

Visual Resources Editorial 2011. Distinguished Leaders in Visual Resources: An Interview with Eleanor Fink, Visual Resources, 15:1, vii-xxii DOI: $10.1080 / 01973762.1999 .9658484$

Zepke, N. and Leach, L. 2010. Improving student engagement: Ten proposals for action. Active Learning in Higher Education, 11(3), 167-177.

Zepke, N. 2013. Threshold concepts and student engagement: Revisiting pedagogical content knowledge. Active Learning in Higher Education, 14(2), 97-107. 